\title{
Adult bipolar diathermy circumcision and related procedures in adults - a safe and efficient technique
}

This article was published in the following Dove Press journal:

Research and Reports in Urology

12 June 2014

Number of times this article has been viewed

\section{Sunny Nalavenkata \\ Matthew Winter \\ Rachel Kour \\ Nam-Wee Kour \\ Paul Ruljancich}

Department of Urology, Eastern Health, Box Hill Hospital, Box Hill, VIC, Australia
Correspondence: Matthew Winter Department of Urology, Eastern Health, Nelson Road, Box Hill Hospital, Box Hill, VIC 3I28, Australia Email matthewwinter0I@gmail.com
Objectives: To present our novel technique and step-by-step approach to bipolar diathermy circumcision and related procedures in adult males.

Methods: We reviewed our technique of bipolar circumcision and related procedures in 54 cases over a 22-month period at our day procedure center. Bipolar diathermy cutting and hemostasis was performed using bipolar forceps with a Valleylab machine set at 15. Sleeve circumcision was used. A dorsal slit was made, followed by frenulum release and ventral slit, and was completed with bilateral circumferential cutting. Frenuloplasties released the frenulum. Preputioplasties used multiple 2-3 mm longitudinal cuts to release the constriction, with frenulum left intact. All wounds were closed with interrupted 4/0 Vicryl Rapide ${ }^{\mathrm{TM}}$.

Results: A total of 54 nonemergency bipolar circumcision procedures were carried out from November 2010-August 2012 (42 circumcisions, eight frenuloplasties, and four preputioplasties). Patients were aged 18-72 years (mean, 34 years). There was minimal to no intraoperative bleeding in all cases, allowing for precise dissection. All patients were requested to attend outpatient reviews; three frenuloplasty and two circumcision patients failed to return. Of the remaining 49, mean interval to review was 49 days, with a range of 9-121 days. Two circumcision patients reported mild bleeding with nocturnal erections within a week postoperatively, but they did not require medical attention. Two others presented to family practitioners with possible wound infections which resolved with oral antibiotics. All 49 patients had well-healed wounds.

Conclusion: The bipolar diathermy technique is a simple procedure, easily taught, and reproducible. It is associated with minimal bleeding, is safe and efficient, uses routine operating equipment and is universally applicable to circumcision/frenuloplasty/preputioplasty. In addition, it has minimal postoperative complications, and has associated excellent cosmesis.

Keywords: circumcision, frenuloplasty, preputioplasty, bipolar, diathermy

\section{Introduction}

Circumcision is one of the most commonly performed and ancient surgical procedures. ${ }^{1,2}$ Despite the longevity of circumcision, the current surgical approach and the instrumentation used vary extremely. ${ }^{3}$ The use of scalpel, scissors, yttrium aluminum garnet lasers, diathermy instruments, and clamp devices have all been described. ${ }^{1-6}$ The use of bipolar diathermy has been described in pediatric patients with successful results as has the use of bipolar scissors in both pediatric and adult patients. ${ }^{1,2,7}$

The technique of bipolar diathermy forceps for cutting and coagulation to perform male adult circumcision and related procedures has not been described in the literature.

We present our novel technique of bipolar diathermy circumcision and related procedures in adult males. 


\section{Methods}

We reviewed our technique of bipolar circumcision and related procedures in 54 cases over a 22 -month period at our day procedure center. All procedures were carried out by a resident assisted by the fellow and performed under general anesthesia. All patient subjects provided written, informed consent and guarantees of confidentiality. The ethical principles of the World Medical Association Declaration of Helsinki were followed for the purpose of this research. An outline of our surgical approach and technique for circumcision is detailed here.

\section{Indication/patient selection}

Bipolar circumcision should be considered in any patient who meets the standard indications for circumcision. Patients with increased bleeding tendency or on anticoagulation or antiplatelet agents are potentially ideal candidates for this operation.

\section{Specific equipment/materials}

The technique involves the standard supine position and preparation. Institutional protocol of deep vein thrombosis prophylaxis and antibiotic usage is adhered to at the induction of general anaesthesia.

We use reusable medical and optical bipolar forceps with a Valleylab Force FX ${ }^{\mathrm{TM}}$ Electrosurgical Generator (Covidien, Mansfield, MA, USA) with the bipolar diathermy set to 15 bipolar. The key to skin cutting with bipolar diathermy is to take small bites of approximately $2-3 \mathrm{~mm}$, applying the diathermy current and then applying a small degree of upward torque. This technique allows for division of tissue and simultaneous hemostasis; hence, we call it "diathermycut." No other cutting instruments are required.

\section{Operative technique: bipolar circumcision}

We perform a sleeve circumcision:

- Step 1 - Dorsal slit. Using bipolar diathermy, perform a dorsal slit by dividing the prepuce from the distal opening. In patients with chronic scarring, we diathermy-cut the inner layer first, then the outer layer. When the skin is thin enough, we diathermy-cut both layers together (Figure 1A).
- Step 2 - Frenulum release. Retract the prepuce and perform a frenulum release (Figure 1B).

- Step 3 - Ventral slit. Place the prepuce on stretch and perform a ventral slit (Figure 1C).

- Step 4 - Circumferential excision. Place the prepuce on gentle traction, perform a circumferential division, and complete the removal of the prepuce. Extend the penile shaft out as long as possible when doing the circumferential cut, to prevent too much skin from being removed. The best distance from the edge of the corona of the glans to the cutting edge of the inner layer of skin is about 4-5 $\mathrm{mm}$. This distance allows enough of an edge to place sutures and yet not too much to allow the foreskin to roll forward. The excised prepuce will leave an exposed superficial layer of the penile shaft (Figure 1D and E).

- Step 5 - Closure. Close the defect with interrupted absorbable sutures, either 4/0 Vicryl Rapide (Ethicon Endo-Surgery Inc., Cincinnati, Ohio, USA) or 4/0 plain catgut; our preference is Vicryl Rapide. A dorsal penile nerve block using $20 \mathrm{~mL}$ of $0.5 \%$ Marcaine $^{\mathrm{TM}}$ (Carestream Dental, Atlanta, GA, USA) is then performed for postoperative analgesia.

\section{Related procedures}

Frenuloplasties involved releasing the frenulum, while preputioplasties used multiple $2-3 \mathrm{~mm}$ longitudinal cuts to release the constriction band. Closure with Vicryl Rapide was performed in the transverse plane.

\section{Postoperative care}

At the conclusion of the procedure, a Jelonet dressing (Smith and Nephew plc, London, UK) with gauze lightly wrapped around the penile shaft is applied. The patient is discharged on the same day with simple analgesia of choice. The dressing remains intact until it falls off. The patient is reviewed at approximately 6 weeks postoperatively.

\section{Results}

Fifty-four bipolar procedures were carried out (42 circumcisions, eight frenuloplasties, and four preputioplasties).
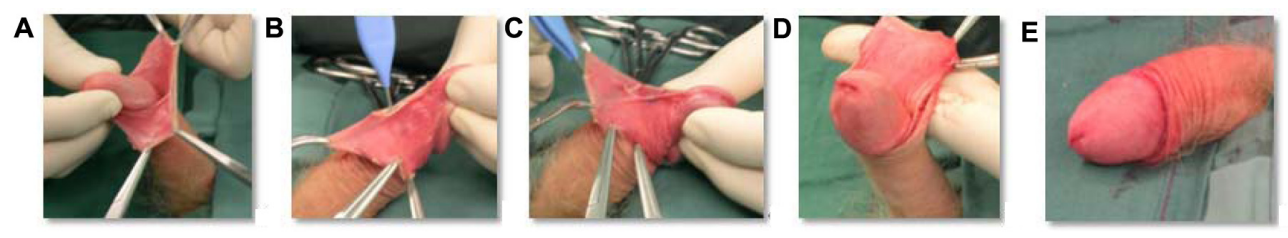

Figure I Sleeve circumcision.

Notes: Completed circumcision prior to closure: (A) dorsal slit; (B) frenular release; (C) ventral slit; (D) bilateral circumferential cutting; (E) completed circumcision. 
The 42 circumcisions were performed for phimosis (36), balanitis xerotica obliterans (four), and balanitis (two). Patients were aged 18-72 years (mean, 34 years). There was minimal to no intraoperative bleeding in all cases, allowing for a precise and unhurried operative technique. Operative time taken was not recorded because it was a teaching procedure; however, in one case, it took 15 minutes from first cut to last stitch.

Two circumcision patients reported mild bleeding with nocturnal erections within a week postoperatively, but they did not require medical attention. Two others presented to family practitioners with possible wound infections which resolved with oral antibiotics. There were no other reported complications. Five patients were lost to follow-up; however, all remaining 49 patients reviewed had well-healed wounds with excellent cosmesis.

\section{Discussion}

Circumcision is one of the most commonly performed surgical procedures and generally quite straightforward. ${ }^{4,8,9}$ However, the most common and problematic aspect of the procedure is the time to complete hemostasis and the ooze associated with excision of a highly vascular skin segment., Thus, any modality that can be implemented to decrease this complication could have significant beneficial outcomes.

Skin incisions are historically made using a scalpel; however, electrocautery has shown equivalence if not superior outcomes with respect to significantly less blood loss and shorter incision times. ${ }^{10}$ Wound complication rate and pain score appears to be no different when comparing the two modalities. ${ }^{10}$ Monopolar diathermy in the use of circumcision has been estimated to reduce bleeding by $90 \%$; however, there is a theoretical risk of penile injury. ${ }^{3,4}$ Bipolar diathermy is the recommended choice for electrosurgery when conducting circumcision, due to the avoidance of penile injury due to its lower current that flows only between the tips. ${ }^{3}$

A recent prospective randomized study comparing bipolar circumcision with the conventional dorsal circumcision technique in children showed that the incidence of bleeding and operative time was significantly less in the bipolar group. There was no difference in the infection rate between the two techniques. ${ }^{8}$ One study showed bipolar diathermy for cutting and coagulation to be effective in the pediatric population with no postoperative bleeding reported. ${ }^{9}$ The postoperative bleeding rate (two of 54) in our study group is likely due to our adult population and the inflammatory pathology that leads to requiring intervention.

The use of bipolar diathermy forceps for hemostasis during circumcision in the adult population has been described and showed almost equivalence in bleeding rates, when compared with standard ties. ${ }^{7}$ However, the use of bipolar diathermy for both cutting and coagulation - to the best of our knowledge - has not been described in the adult population.

Our technique of bipolar diathermy circumcision and related procedures in adults is a simple procedure - easily taught and reproducible. It is associated with: minimal bleeding; safety and efficiency; and is universally applicable to circumcision, frenuloplasty, and preputioplasty. It has minimal postoperative complications and is associated with exceptional cosmesis.

\section{Acknowledgment}

This paper was presented at the 66th Annual Scientific Meeting of the Urological Society of Australia and New Zealand, Melbourne, Australia, April 13-16, 2013.

\section{Disclosure}

The authors report no conflicts of interest in this work.

\section{References}

1. Fraser ID, Tjoe J. Circumcision using bipolar diathermy scissors: a simple, safe and acceptable new technique. Ann R Coll Surg Engl. 2000;82(3):190-191.

2. Peters RT, Fisher R. Paediatric circumcision using bipolar diathermy. Ann R Coll Surg Engl. 2009;91(5):436.

3. Tucker SC, Cerqueiro J, Sterne GD, Bracka A. Circumcision: a refined technique and 5 year review. Ann R Coll Surg Engl. 2001;83(2): 121-125.

4. Elder JS. Circumcision. BJU Int. 2007;99(6):1553-1564.

5. Li G, Li Q, Fu WJ, et al. Modified one-cut circumcision technique by clamp: reports of 2000 cases. Chin Med J (Engl). 2010;123(19): 2732-2735.

6. O'Sullivan DC, Heal MR, Powell CS. Circumcision: how do urologists do it? Br J Urol. 1996;78(2):265-270.

7. Marsh SK, Archer TJ. Bipolar diathermy haemostasis during circumcision. Br J Surg. 1995;82(4):533.

8. Fariz MM, Tarmizi MN, Ainaini MH, Khairil AM, Faizal A, Sagap I. A prospective randomised comparison of bipolar diathermy versus conventional dorsal slit technique for ritual circumcision: a Malaysian experience. Clin Ter. 2011;162(6):543-545.

9. Fearne C. Point of Technique. Bloodless circumcision. BJU Int. 1999;83(6):717.

10. Ly J, Mittal A, Windsor J. Systematic review and meta-analysis of cutting diathermy versus scalpel for skin incision. Br J Surg. 2012;99(5): 613-620. 


\section{Publish your work in this journal}

Research and Reports in Urology is an international, peer-reviewed, open access journal publishing original research, reports, editorials, reviews and commentaries on all aspects of adult and pediatric urology in the clinic and laboratory including the following topics: Pathology, pathophysiology of urological disease; Investigation and treatment of

urological disease; Pharmacology of drugs used for the treatment of urological disease. The manuscript management system is completely online and includes a very quick and fair peer-review system, which is all easy to use. Visit http://www.dovepress.com/testimonials.php to read real quotes from published authors.

Submit your manuscript here: http://www.dovepress.com/research-and-reports-in-urology-journal 